\title{
COMMENTARY
}

\section{Relation between colour vision loss and occupational styrene exposure}

\section{K Viaene}

Occup Environ Med 2003;60:222

This commentary relates to the study by Gong et al, published in the December 2002 issue of this journal.

A part from uncertainties on study design adequacy and possible selection bias inherent to cross sectional studies, other issues often emerge from such studies in the industrial setting when trying to link rather subtle subclinical effects with neurotoxicant exposure. This is also the case in the study by Gong and colleagues, ${ }^{1}$ dealing with increased colour confusion index (CCI) in occupational styrene exposure. For instance, which characteristic of the exposure causes the effect? Is it the duration of exposure, the average level, or the peak exposure level, or is it a combination of these? What is the implication of this subtle effect on the health status of the exposed individual? Is it persistent when exposure ceases? Is it a sensitive indicator for other neurotoxic effects which are more difficult to measure (for example, neurobehavioural or neurochemical effects)? Does it predict progression to more widespread toxicity in the central nervous system if exposure continues?

The study by Gong et al tries to answer some of these questions. Estimating cumulative past exposure to a solvent is difficult. By expressing the cumulative exposure index (CEI) of styrene as a multiple of years exposed to $20 \mathrm{ppm}$ is assuming that the potential toxicity of four years at $20 \mathrm{ppm}$, for example, equals that of one year at $80 \mathrm{ppm}$. In view of the literature, this may be questioned. Indeed, Edling and colleagues ${ }^{2}$ did not find significant effects on visuomotor performance in styrene workers (average nine years of exposure to $10 \mathrm{ppm}$ ), whereas Letz and colleagues ${ }^{3}$ did (average 2.9 years of exposure to $\geqslant 50$ ppm). Thus, calculating the CEI as proposed by Gong et al may blur the relation between CEI and CCI. The authors also suggest that colour vision impairment seems to be a very sensitive indicator of partially irreversible styrene toxicity which can be detected in workers with very low current styrene exposure, for example, $<10 \mathrm{ppm}$. This should be taken with caution as it is based on a dichotomous stratification of the study population with an arbitrary boundary value of current urinary $\mathrm{MA}+\mathrm{PGA}=0.24 \mathrm{~g} / \mathrm{g}$ creatinine, which points to a mean styrene exposure of about $10 \mathrm{ppm}$, but no information is given on peak exposure levels. Moreover, fig 2 shows that this population was exposed in the past to 3-4 times higher mean (large SD) concentrations of styrene, which supports the authors' second hypothesis of persistent effects of high past exposure, even if these levels were limited in time. Therefore, occupational hygienic strategies must in the first place eliminate the possibility of peak styrene exposure levels, rather than focusing on maintaining low average exposures (as expressed by low average end shift urinary concentrations of MA and PGA).

So far, temporal or predictive relations between declining colour vision and diminishing neuroperformance have not yet been studied for styrene or other solvent exposures. As the Lanthony desaturated D-15 test is very easy to perform, it would be interesting to exploit prospective repeat measurements of CCI to predict who will or who has developed subclinical neurobehavioural damage. However, it could well be that the mechanisms of toxic action of styrene are in the retina different from those operating in the central nervous system. Further prospective as well as fundamental research is certainly needed.

\section{Author's affiliation}

M K Viaene, Department of Occupational Health, Catholic University of Leuven, Belgium; Governmental Psychiatric Hospital, Geel, Belgium

Correspondence to: Dr M K Viaene, Department of Occupational Medicine, University Hospital St Rafaël, p/a Pas 285, 2440 Geel, Belgium; leenders.viaene@pandora.be

Accepted 27 June 2002

\section{REFERENCES}

1 Gong Y, Kishi R, Katakura Y, et al. Relation between colour vision loss and occupational styrene exposure level. Occup Environ Med 2002;59:824-9.

2 Edling C, Anundi H, Johanson $G$, et al. Increase in neuropsychiatric symptoms after occupational exposure to low levels of styrene. $\mathrm{Br} J$ Ind Med 1993:50:843-50

3 Letz R, Mahoney FC, Hershman DL, et al. Neurobehavioral effects of acute styrene exposure in fiberglas boatbuilders. Neurotoxicol Teratol $1990 ; 12: 665-8$.

Abbreviations: $\mathrm{CCl}$, colour confusion index; $\mathrm{CEl}$, cumulative exposure index; $M A$, mandelic acid; PGA, phenylglyoxylic acid 